\title{
The Orthotropic Neobladder; How to Make It Easy?
}

\author{
Ahmed M Moeen* and Diaa A Hameed \\ Assiut urology and nephrology Hospital, Assiut University, Egypt
}

Submission: February 14, 2017; Published: March 03, 2017

*Corresponding author: Ahmed M Moeen, Assiut urology and nephrology Hospital, Assiut University, Egypt, Email: moeen3@yahoo.com

Abstract

Radical cystectomy and urinary diversion is the standard treatment for patients with muscle invasive bladder cancer. Urinary diversion after radical cystectomy requires skill and expertise. Multiple techniques of urinary diversion are present. However, the orthotropic neobladder (OBS) may be better in terms of quality of life. For the sake of simplicity, neobladder reconstruction is better divided into the following stages;
a. Stage I: Patient selection and preparation
b. Stage II: Radical cystectomy and lymphadenectomy
c. Stage III: Neobladder reconstruction
d. Stage IV: Uretero- and Urethro-enteric anastomosis
e. Stage V : Postoperative management
f. Stage VI: Management of complications

Keywords: Orthotopic neobladder; Reconstruction; Stages; Complications

Abbreviations: RCX: Radical Cystectomy; OBS: Orthotopic Neobladder; ERAS: Enhanced Recovery after Surgery; LND: Lymphadenectomy

\section{Introduction}

Radical cystectomy (RCX) and urinary diversion is the standard treatment for patients with muscle invasive bladder cancer and some patients with non-muscle invasive disease who failed the intra-vesical treatment [1]. Multiple techniques of urinary diversion are present. However, the orthotopic neobladder (OBS) may be better in terms of quality of life, as it is the closest to the normal bladder in location and function. However, it is measured as one of the most difficult urologic procedure [2]. In this short review, we try to simplify the basic principles of neobladder reconstruction for the beginners to make their practice easier. For the sake of simplicity, neobladder reconstruction is better divided into stages; the higher stages need higher experience. We divide it into the following stages;

Stage I: Patient selection and preparation

Stage II: Radical cystectomy and lymphadenectomy

Stage III: Neobladder reconstruction

Stage IV: Uretero- and Urethro-enteric anastomosis

Stage V: Postoperative management

Stage VI: Management of complications

\section{Stage I: Patient selection and preparation}

To start with, successful neobladder reconstruction starts with appropriate patient selection and preparation. The main pillars of this stage that should be well recognized are; the indications, contraindications, how to counsel the patients and the peri-operative preparations.

In general, two important criteria must be maintained in patients indicated for RCX to be eligible for OBS: an intact rhabdosphincter to preserve the urinary continence and the radicality of surgery should not be compromised by the retained membranous urethra to which the neobladder will be anastomosed.

On the contrary, the contraindications are multiple and diverse. This implies that the selection criteria are strict and the patient should be an "A1" patient medically and mentally. It includes, patients indicated for urethrectomy as those with bladder neck tumors and extensive infiltrations of the prostate, urethral sphincteric or stricture diseases, those with permanently compromised renal function or severely impaired liver functions, increased risk of metabolic complications as those with previous bowel resection or sever diverticulosis, 
mental or physical impairments that precludes the ability to self-catheterize when this is necessary, incompliant patients for postoperative regular follow-up, impossibility of nervesparing surgery at least on one side, high dose of peri operative radiotherapy and Age $>80$ years [3]. The age is not an absolute contraindications and the differentiation between the biological and chronological age is the most important. However, the age of 80 may be the stimulus not to do OBS, as it may be associated with a higher incidence of postoperative morbidity but without increased mortality even in high volume centers [4].

Counseling is very critical. The patient should know all the risks and benefits of this surgery. He/she should know that the possibility of conversion to other diversion forms is an option due to any intra-operative oncological, anatomic or anesthetic reasons [3]. Also, the expectation should be realistic, he/she should know that his neobladder is not a new bladder and there is no urinary diversion technique that could replace all the functions of the natural bladder.

RCX needs an extensive preoperative preparation, careful intra-operative and postoperative manipulations to optimize the functional outcomes. In 2014, published in the European urology a 22 items designed for enhanced recovery after Surgery (ERAS). These include; preoperative medical optimization, bowel preparations can be safely omitted, avoidance of long-term sedative, thrombosis prophylaxis, antimicrobial prophylaxis 1 hr before skin incision, skin preparation with Chlorhexidinealcohol to decrease surgical site infection, epidural analgesia should continue for 72 hrs to relieve pain without opioids, careful peri-operative fluid management and avoidance of intraoperative hypothermia, early removal or no nasogastric tube use, prevention of postoperative ileus and nausea and vomiting, early mobilization and early oral diet. They concluded that these ERAS items improve the patient care, decrease the postoperative morbidity and the length of hospital stay [5].

\section{Stage II: Radical cystectomy and lymphadenectomy}

When discussing the stage of RCX, we will not discuss the surgery on details, but we will stress on three important issues; timing of surgery, how quality of RCX and lymphadenectomy will affect the outcome and lastly certain surgical steps should be done carefully and others should be avoided.

First, timing is very critical as it was shown that there is window of opportunity of about 3 months, after which delaying cystectomy may be associated with increase in the risk of progression and cancer specific mortality [6].

Second, how quality of surgery affecting the outcome is evident from the following; positive surgical margin occurs in $4 \%$ with high volume urologists and $14 \%$ in low volume ones. Local recurrence will develop in $6 \%$ of margin negative patients if compared to $68 \%$ of margin positive counterparts. The Mortality rate is about $0.7 \%$ in high volume hospitals and $3.1 \%$ in low volume ones $[7,8]$.
Certain surgical steps during RCX will affect the reconstructive functional outcome greatly. Ureteric dissection should be done carefully to preserve its vascularity and preserve the lower most part of the ureters which is very important factor in reflux prevention. The pressure in the lower part of the ureter is about $20-30 \mathrm{~cm}$ of water and the bladder end filling pressure is $20 \mathrm{~cm}$ for an optimal cystometric capacity of $450 \mathrm{~cm}$. So, this pressure difference is a safety margin [9].

Multiple techniques of dorsal vein ligation are present; it should be done carefully to avoid bleeding. If done so, it will help so much in preparation of the urethral stump in a traumatic way with preservation of a well-functioning urethral length and performing nerve sparing RCX in a visually clear field which not only improve the sexual function but also affect continence status $[10,11]$.

On the contrary, prostatic capsule and seminal sparing RCX should be avoided. It may improve the postoperative erectile function but does not really improve the continence status. In the meantime, $10-15 \%$ higher oncologic failure rate makes it preferably should be avoided [12,13].

Regarding lymphadenectomy (PLND), extended PLND should be considered the standard in patients undergoing RCX as it will clear up to $90 \%$ of the lymph nodes if compared to $50 \%$ nodal yield when a limited PLND is only performed [14]. When an extended PLND was compared to limited one in patients with $\leq$ pT3P N0.2 disease, the 5 years recurrence-free survival was significantly better ( 49 vs. $19 \%$, respectively) [15]. Surprisingly, with expanding the template to the inferior mesenteric artery, similar survival and recurrence rates in $\mathrm{pT} 2-3 \mathrm{cN} 0 \mathrm{cM} 0$ patients were found as extended PLND [16]. This may be due to the lymph node metastases higher than the common iliac bifurcation is a characteristic of systematic disease which cannot be controlled by extensive surgery [17].

\section{Stage III: Neobladder reconstruction}

Certain goals should be achieved to obtain a good reservoir which are; large capacity, low intra-luminal pressure, no reflux, continence preservation and minimal absorption of urinary solutes.

All intestinal segments were extensively studied for reservoir reconstruction. However, the intestinal segment which stood the test of time is the ileum due to the following reasons; it is more distensible if compared to other segments [18], has favorable urodynamic parameters in the form of large capacity, better compliance and lower filling pressure [19], better continence rates if compared with colonic neobladder [20], its mucosal atrophy with less reabsorption of urinary solutes is more reliable than the large bowel [21] and finally the ease with which the small bowel can be surgically manipulated.

Originally, neobladders were reconstructed from larger intestinal segments as the original Studer $(56-60 \mathrm{~cm})$ and 
Hautmann $(70 \mathrm{~cm})$ ileal neobladders to improve the nighttime incontinence [22,23]. However, for more than two decades, $40-45 \mathrm{~cm}$ of the ileum, $25 \mathrm{~cm}$ apart from the ileo-cecal valve proved to be quit sufficient $[24,25]$. The functional capacity will increase within weeks or months from 150 to $500 \mathrm{ml}$. This will decrease the incidence of chronic retention with low intra-luminal pressure [26].The postoperative electrolyte disturbance or metabolic acidosis will be minimized [27]. Also, preservation of the terminal part of the ileum and the ileo-cecal valve will decrease the postoperative diarrhea and vitamin B12 deficiency [28]. The risk of spontaneous rupture will decrease as the tension on the large reservoir when filled with urine is significantly higher than in small reservoir with the same intraluminal pressure [27].

Configuration of the reservoir will affects the functional outcome to a great extent. Detubularization and cross folding will minimize the development of high pressure peaks. A spherical reservoir has multiple advantages, the maximum radius according to Laplace's law will be obtained, so the maximum volume to surface area ratio with lower end filling pressure will results. Also, higher wall tension (tension=pressure $\times$ radius) in response to the urethral closure pressure will make the sensation of fullness is more likely [3]. Also, there is metabolic advantage as the length of the bowel resection and the area available for reabsorption from the reservoir are minimized [29].

\section{Stage IV: Uretero- and Urethro-enteric anastomosis}

The uretero-enteric and urethro-enteric anastomosis are two risky steps during neobladder reconstruction. Improper reconstruction will endanger the upper urinary tract or the whole urinary tract respectively. Good anastomosis should be tension free, water tight, mucosa to mucosa and stunted. Regarding ureteric reimplantation, to do or not to do antirefluxing technique is a matter of debate [30]. However, the stricture rate is generally higher with anti-refluxing techniques. Regarding the urethro-enteric anastomosis, there are 2 types of neourethra; hole and non-hole techniques. In order to perform safe urethro-enteric anastomosis, we should preserve wellfunctioning urethral length and prepare the urethral Stump carefully, the neourethra should be wide button hole, most dependent, mucosa to mucosa, tension free with no leakage or tube anastomosis. If the urethro-enteric anastomosis is under tension, certain sequential steps should be performed; careful selection of bowel loops, opening of the peritoneum covering the mesentery, releasing the mesenteric fat, removing the sigmoid colon out of the pelvis, reducing the steep of trendelnburg positioning angle, perineal pressure and freeing the right colonic junction and moving the ileum and the right colon downwards.

\section{Stage V: Post-operative management}

Meticulous postoperative care and life-long follow up are very critical for good long-term results [23]. In the immediate postoperative setting, thrombosis prophylaxis by subcutaneous heparin should be administered preferably in the arm instead of the thigh to prevent lymphocyte. The neobladder should be irrigated gently and frequently to avoid mucous accumulation. Bowel stimulation with para sympathomimetics should be instituted from day 2 or 3 . Serial body weight and blood gas analysis should be measured [3].

Regarding the catheters and stents, the time of their removal is debated. Originally, the ureteric catheters, supra-pubic tube and the urethral catheters were removed at about 10, 12 and 21 days respectively. However, in updated experience of some experts, they stated that they could be removed at days 5-7, 8-10 (after cystogram) and at 10-12 respectively [3].

Following catheter removal, patients are carefully instructed how to void. Initially, in a sitting position every $2 \mathrm{~h}$ during the day by slight increase the intra-abdominal pressure. Thereafter every $3 \mathrm{~h}$; later every $4 \mathrm{~h}$ until approaching a capacity of 400-500 $\mathrm{ml}$. use of alarm clock at night to avoid nocturnal enuresis.

Serial check of the residual urine, urine analysis, venous blood gas analysis and supplement of bicarbonate (2-6g) and salt whenever indicated should be performed. Long-term followup is very important to early detect and manage the following events; metabolic complications (vitamin B12, electrolytes, base excess), voiding complains (incontinence, difficulty and increased mucous production due to infection), occurrence of delayed complications (neobladder outlet obstruction or uretero-enteric strictures) and oncological failure [3].

\section{Stage VI: Management of complications}

RCX is the most difficult urologic procedure with a wide range of peri-operative complications even with most experienced surgeons with a post operative complications rate of $25-57 \%$. However, the rate of severe and lethal complications is acceptably low with in-hospital mortality of $3 \%$ and re-operative rates of $2.3-17 \%$. The complications should be classified by the fivegrade modification of the original Clavien system [3].

Management of neobladder complications requires patience and expertise. It could be managed either by endoscopic, laparoscopic or open surgery routes. But, the minimally invasive endoscopic management should be tried first, whenever possible. As it saves a lot of hazards that may occur with laparoscopic or open surgery due to marked intra-abdominal adhesions and allows the patient to return faster to normal daily activity. Uretero-enteric stricture, pouch stones, recurrent neobladder tumors, urethral recurrence and urethro-enteric stenosis all could be managed endoscopically [28].

\section{Conclusion}

In conclusion, RCX and OBS is an advanced multi-steps urologic procedure. To make it easy, certain precautions should be followed. We should carefully select our patients. Standard RCX and extended PLND should be performed. Dorsal vein ligation and urethral stump preparation should be done cautiously as they are risky key steps. Familiarity with other 
urinary diversion techniques is important for the urologistas intra-operative findings may change the plane. Regular lifelong follow up for delayed complications is important. For best results, a regular skilled operative team and a high volume wellequipped hospital with high case load are mandatory.

\section{References}

1. Hautmann RE, de Petriconi RC, Pfeiffer C, Volkmer BG (2012) Radical cystectomy for urothelial carcinoma of the bladder without neoadjuvant or adjuvant therapy: long-term results in 1100 patients. EurUrol 61(5): 1039-1047.

2. Montie JE (1996) Technique of radical cystectomy in the male. In: Marshall FF, Kavoussi LR, McAninch JW, Peters CA (Eds.), Text book of operative urology. Saunders Company, Philadelphia, USA, pp. 396-407.

3. Richard E Hautmann, Henry Botto, Urs E Studer (2009) How to Obtain Good Results with Orthotopic Bladder Substitution: The 10 Commandments. European urology supplements 8(9): 712-717.

4. Kessler TM, Burkhard FC, Permenis P, Danuser H, Thalmann GN, et al. (2005) Attempted nerve-sparing surgery and age have a significant effect on urinary continence and erectile function after radical cystoprostatovesiculectomy and ileal orthotopic bladder substitution. J Urol 32(2): 165-175.

5. Hitendra RH Patel, Yannick Cerantola, Massimo Valerio, Beata Persson, Patrice Jichlinski, et al. (2004) Enhanced Recovery After Surgery: Are We Ready, and Can We Afford Not to Implement These Pathways for Patients Undergoing Radical Cystectomy? EurUrol 65(2): 263-266.

6. Fahmy NM, Mahmud S, Aprikian AG (2006) Delay in the surgical treatment of bladder cancer and survival: systematic review of the literature. Eur Urol 50(6): 1176-1182.

7. Harry W Herr, James R Faulkner, H Barton Grossman, Ronald B Natale, Ralph de Vere White, et al. (2004) Surgical factors influence bladder cancer outcomes: a cooperative group report. J Clin Oncol 22: 27812789.

8. Elting LS, Pettaway C, Bekele BN, Grossman HB, Cooksley C, et al. (2005) Correlation between annual volume of cystectomy, professional staffing and outcomes. Cancer 104(5): 975-984.

9. Buzelin JM (1993) Physiology and functional explorations of the surgical pathway. Report to the $87^{\text {th }}$ Congress of Urology Paris, France.

10. Hekal IA, El-Bahnasawy MS, Mosbah A, El-Assmy A, Shaaban A (2009) Recoverability of erectile function in post-radical cystectomy patients: subjective and objective evaluations. Eur Urol 5(2): 275-283.

11. Kessler TM, Burkhard FC, Studer UE (2005) Clinical indications and outcomes with nerve sparing cystectomy in patients with bladder cancer. UrolClin North Am 32(2): 165-175.

12. Hautmann RE, Stein JP (2005) Neobladder with prostatica capsule and seminal sparing cystectomy for bladder cancer: a step in the wrong direction. UrolClin North Am 32(2): 177-185.

13. Botto H, Sebe P, Molinie' V, Herve J, Yonneau L, et al. (2004) Prostatic capsule and seminal-sparing cystectomy for bladder carcinoma: initials results for selected patients. BJU Int 94: 1021-1025.
14. Roth B, Wissmeyer MP, Zehnder P, Birkhauser FD, Thalmann GN, et al. (2010). A new multimodality technique accurately maps the primary lymphatic landing sites of the bladder. Eur Urol 57(2): 205-211.

15. Dhar NB, Klein EA, Reuther AM, Thalmann GN, Madersbacher S, et al. (2008) Outcome after radical cystectomy with limited or extended pelvic lymph node dissection. J Urol 179(3): 873-878.

16. Zehnder P, Studer UE, Skinner EC, Dorin RP, Cai J, et al. (2011) Super extended versus extended pelvic lymph node dissection in patients undergoing radical cystectomy for bladder cancer: a comparative study. J Urol 186(4): 1261-1268.

17. Roth B, Thalmann GN (2015) Standard Cystectomy fits all: myth or truth. Transl Androl Urol 4(3): 254-260.

18. Hohenfellner M, Bürger R, Schad H, Heimisch W, Riedmiller H, et al. (1993) Reservoir characteristics of Mainz pouch studied in animal model. Osmolality of filling solution and effect of oxybutynin. Urology 42(6): 741-746.

19. Schrier BP, Laguna MP, van der Pal F, Isorna S, Witjes JA (2005) Comparison of orthotopic sigmoid and ileal neobladders: continence and urodynamic parameters. Eur Urol 47(5): 679-685.

20. Kurzrock EA, Tomasic NA, Razi SS, Skinner DG, Bennett CJ (1995) Fluoro urodynamic and clinical evaluation in males following construction of a Kock ileal-urethral reservoir. Urology 46(6): 801-803.

21. Studer UE, Burkhard F, Danuser HJ, Thalmann G (1999) Keys to success in orthotopic bladder substitution. Can J Urol 6(5): 876-877.

22. Studer UE, Burkhard FC, Schumacher M (2006) Twenty years' experience with an ileal orthotopic low pressure bladder substitute, lessons to belearned. J Urol 176(1): 161-166.

23. Hautmann RE, Egghart G, Frohneberg D, Miller K (1988) The ileal neobladder. J Urol 139(1): 39-42.

24. Abol-Enein H, Ghoneim MA (2001) Functional results of orthotopic ileal neobladder with serous-lined extramural ureteral reimplantation: experience with 450 patients. J Urol 165(5): 1427-1432.

25. Sevin G, Soyupek S, Armagan A, Hoșcan MB, Oksay T (2004) Ileal orthotopic neobladder (modified Hautmann) via a shorter detubularized ileal segment: experience and results. BJU Int 94(3): 355-359.

26. Kreder K, Das AK, Webster GD (1992) The hemi-Kockileo cystoplasty: a versatile procedure in reconstructive urology. J Urol 147(5): 12481251.

27. Keetch DW, Klutke CG, Catalona WJ (1992) Late decompensation of neobladder. J Urol 148(3): 806-810.

28. Rogers E, Scardino PT (1995) A simple ileal substitute bladder after radical cystectomy: experience with a modification of the Studer pouch. J Urol 153(5): 1432-1438.

29. Studer UE, Zingg EJ (1997) Ileal orthotopic bladder substitutes. What we have learned from 12 years' experience with 200 patients. Urol Clin North Am 24(4): 781-793.

30. Hautmann RE, Abol-Enein H, Davidsson T, Gudjonsson S, Hautmann SH, et al. (2013) ICUD-EAU International Consultation on Bladder Cancer 2012: Urinary diversion. Eur Urol 63(1): 67-80. 
(c) (1)

This work is licensed under Creative

Commons Attribution 4.0 License

DOI: $10.19080 / J O J U N .2017 .2 .555580$
Your next submission with Juniper Publishers will reach you the below assets

- Quality Editorial service

- Swift Peer Review

- Reprints availability

- E-prints Service

- Manuscript Podcast for convenient understanding

- Global attainment for your research

- Manuscript accessibility in different formats

( Pdf, E-pub, Full Text, Audio)

- Unceasing customer service

Track the below URL for one-step submission https://juniperpublishers.com/online-submission.php 